\title{
Impact of mine waste on the quality of surrounding agricultural soils in Toussit and Sidi Boubker, Morocco: a case study
}

\author{
Khalida Bouali $^{1 *}$, Mourad Arabi ${ }^{1}$, Latifa Mechkirrou ${ }^{2}$, and Abdelhafid chafi $^{1}$ \\ ${ }^{1}$ Laboratory for Improvement of Agricultural Production, Biotechnology and Environment (LAPABE). Faculty of Science, \\ Mohammed Premier Oujda University, Morocco. \\ ${ }^{2}$ Laboratory of Agro-Physiology, Biotechnologies, Environment and Qualities, Faculty of Sciences, PB 242 14000, Kenitra, \\ Morocco
}

\begin{abstract}
The Oriental region, in Morocco, is surrounded by the Algerian border to the East, the Atlas to the West, the Mediterranean to the North and the desert to the south. This region has benefited from the intense mining activity that has played an important role in the national economy. The intensification of mining activity in the Touissit and Sidi-Boubker mines has left behind the closure of tons of waste in the shelter without a plan of conservation. These mine waste storage sites still contain very high levels of metallic elements such as Iron (Fe), which, after a decade of shutdowns, are likely to pollute vulnerable receiving environments, posing a threat to wildlife ecosystems, flora, and to public health. The objective of this study was to assess Fe concentrations at several locations around these mine waste heaps. The results of physicochemical analyses of soils collected over two different periods (wet and dry seasons) showed maximum Fe element concentrations of $10596 \mathrm{mg} / \mathrm{kg}$, with an average concentration of $8913 \mathrm{mg} / \mathrm{kg}$. These Iron contents are found at concentrations exceeding tolerance standards for normal soil. Keywords: Mining activity, Touissit-Sidi boubker, Metal trace elements, Pollution, Morocco.
\end{abstract}

\section{Introduction}

The industrial activity of mining in the eastern region of Morocco was very intense because of its geological particularity which favoured the presence of different metals and metal indices. The sites of Sidi Boubker and Touissit, located at $30 \mathrm{~km}$ south of the city of Oujda, ended there mining operation in 1975 and 2002, respectively, due to the reserves depletion, after an exploitation of nearly 40 years for Sidi Boubker and 75 years for Touissit [1]. Indeed, the production of metallic concentrates at these two sites was done by the differential flotation process which generated the dikes (mountains of mine waste) which constitute a source of serious pollution for the region and the inhabitants in the vicinity [2].

These mine waste storage sites consisting of mill tailings and waste rock are sheltered without a development plan or rehabilitation. Moreover, the fact that the Touissit mine was productive for 75 years has allowed it to play a very important economic role. Indeed, this site has been one of the main sources of life for a large population. In fact, an estimated 1,000 employees were expected to benefit from this activity, 130 of whom were of European origin [3]. On the other hand, it is noted that this activity generated between the year 1926 and 1997 a quantity of 67 million tons of mines which highlights the important deposit of co-produced mine waste. Thus, the use of chemical reagents during purification phases requires consideration of all possible impacts on the receiving environments that may be induced through this waste abandoned on site [4].
As reported by Hakkou \& Benzaazoua in 2012 [5], there are about 200 abandoned mining sites in Morocco.

The purpose of this work was to assess the impact of mining activity on the district of Touissit and Boubker through the measurement of the contents of some metal elements in soil samples taken from mine waste storage site and from fields located in their vicinity. This will help to highlight the migration potential of iron metal, which is one of the major metal pollutants making up this waste.

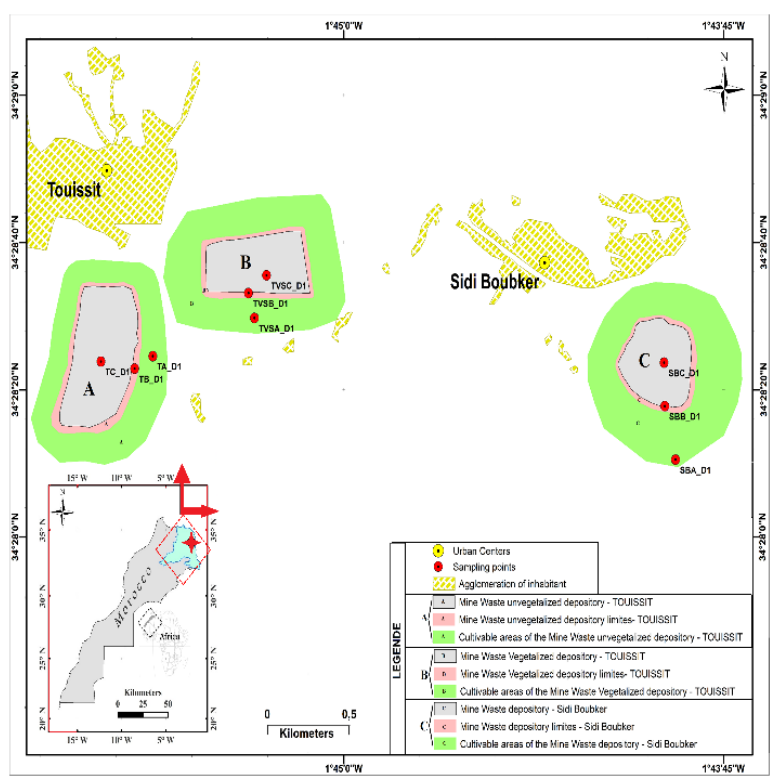

Fig. 1. Geographical location of sampling sites in the Touisssit and Sidi-Boubker areas. 


\section{Materiel and Methods}

The district of Touissit-Boubker houses four storage sites of mine waste (Boubker, Touissit, Beddiane and Mekta). Three sites were sampled at different depths (Figure 1): Sidi Boubker mines waste storage site (SB), Touissit mines waste storage site $(\mathrm{T})$, and Touissit mines waste storage site with Vegetated soil (Tv).

Sampling also took place at the field soil level in the vicinity of the study site at different depths to monitor migration of metallic elements into agricultural soil in order to show that the impact of trace metal elements is not punctual but diffuse and can reach other vulnerable areas which constitute a threat to the fauna and flora of the area and also to human health. The parameters studied in this study, given their importance in the release of metallic elements, were $\mathrm{pH}$, conductivity and carbonates. The $\mathrm{pH}$ was measured following liquidsolid extraction method using a pH meter (Hanna-330) [6]. Iron (Fe) is determined following Inductively Coupled Plasma-atomic emission spectrometry (ICPAES, Ultima2 JY) [7]. The two companions were conducted during the wet season in December 2017 and the second was conducted during the month of July in 2018 .

\section{Results and discussions}

\section{$3.1 \mathrm{pH}$}

The $\mathrm{pH}$ was slightly acidic to neutral due to the existence of carbonates that bring the $\mathrm{pH}$ towards neutrality.

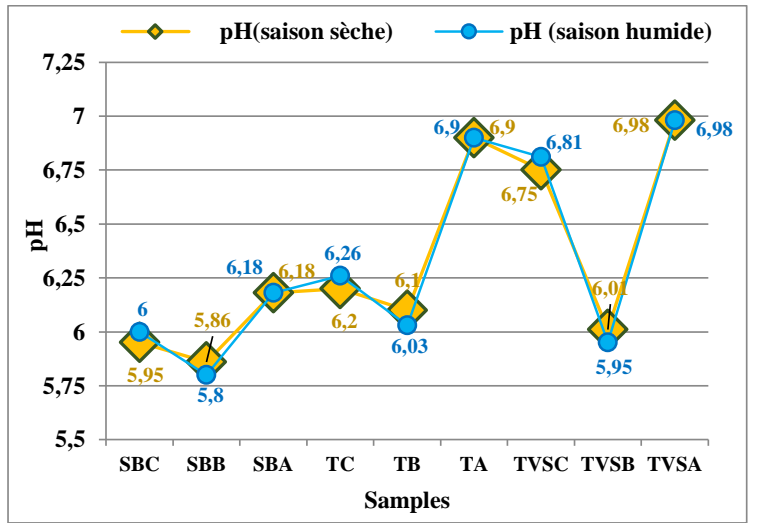

Fig. 2. pH variation during both dry and wet seasons

Soil samples from the Sidi Boubker dike (SBS and SBB) showed the lowest $\mathrm{pH}$ values (5.95-6) and (5.8 5.86) for the two successive seasons. These highly acidic values can be explained by the absence of plant cover, which favours hydro-chemical reactions in the absence of the buffer effect of the flora. However, in areas with spontaneous vegetative cover even with low to medium density (TV, TVSB and TVSA), the presence of cultivated grass species and shrubs gives the soil a $\mathrm{pH}$ with a neutral tendency close to 7 .

\subsection{Electrical Conductivity (EC)}

The EC variation in CE measured in three study areas is shown in Figure 3.

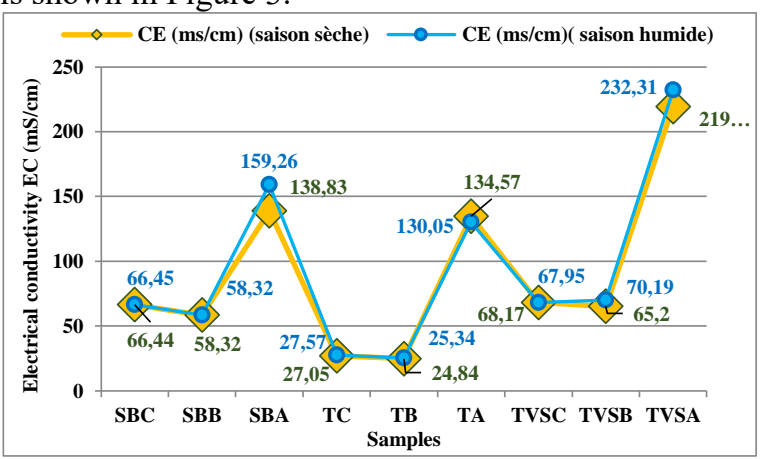

Fig.3. The electrical conductivity measured during both dry and wet seasons

Electrical conductivity was strongly demonstrated at the SBA, TA and TVSA points with maximum values of $159.26 \mathrm{mS} / \mathrm{cm}, 143.57 \mathrm{mS} / \mathrm{cm}$ and $232,31 \mathrm{mS} / \mathrm{cm}$ successively. The minimum values were measured for TC and TB soils $(27.05 \mathrm{mS} / \mathrm{cm}$ and $24.84 \mathrm{mS} / \mathrm{cm})$ successively. The maximum EC' values were measured for soils highly exposed to air and moisture arriving during cold periods of the year. This exposure is caused by hydro-chemical mineralization reactions, which increases the risk of acid mine drainage to the depth. Indeed, these soils, which are already known for their very high mineral load, are more intense than those of the soils far from these deposits, which are planted in grasses, providing them with stability through the organic matter presence.

\subsection{Iron ( $\mathrm{Fe})$ content in the study area}

Enormous levels of Iron elements were measured at all sampling points in the study area and during both seasons (Figure 5). The minimum $\mathrm{Fe}$ concentration measured during the wet season $(5739 \mathrm{mg} / \mathrm{kg})$ exceeded the standard of normal soil as described by Baize (1997) [8]. Indeed, this value also exceeded the value requiring intervention for correction of contaminated soil (Figure 4). Veleur pour in sol typique

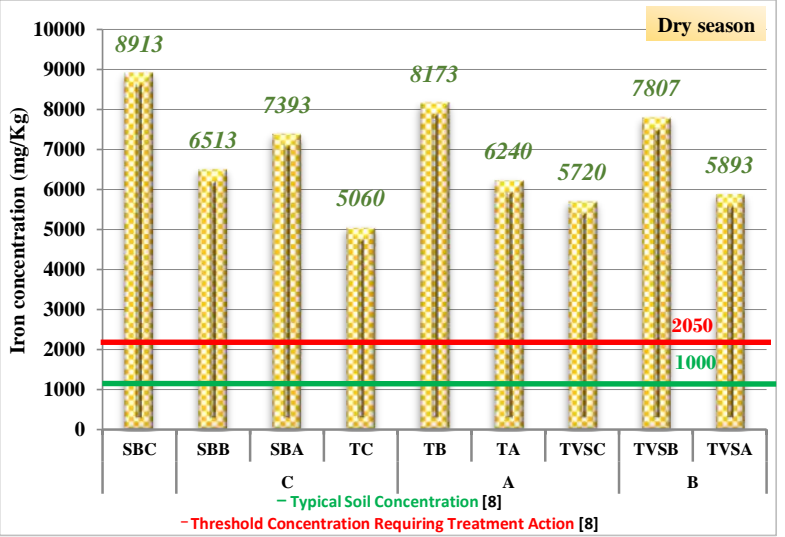

Fig. 4. Iron $(\mathrm{Fe})$ concentration measured during the dry season 
The maximum Fe content is noted at the top of the SidiBoubker mine waste storage site (zone C at SBC) (8736 $\mathrm{mg} / \mathrm{kg}$ ) while the minimum content is measured at the top of the Touissit mine mine waste storage site with no vegetation (zone A at TC) $(4886 \mathrm{mg} / \mathrm{kg})$. For the dry season the Fe maximum content is $8913 \mathrm{mg} / \mathrm{kg}$ and the minimum is $5060 \mathrm{mg} / \mathrm{kg}$.

These enormous levels are also seen in the agricultural soils surrounding the mine mine waste storage site. The maximum $\mathrm{Fe}$ concentration is detected on the agricultural soil of Sidi-Boubker (zone ' $C$ ' at SBA), during the dry season $(7393 \mathrm{mg} / \mathrm{kg})$. While the minimum content is $5893 \mathrm{mg} / \mathrm{kg}$ on the agricultural soil of the Touissit site with vegetation (zone 'B' at TVSA) (Figure 4). During the wet season, these maximum levels were recorded at the Sidi-Boubker site (7308 $\mathrm{mg} / \mathrm{kg}$ ), while the minimum levels were measured at the Touissit vegetated site $(5739 \mathrm{mg} / \mathrm{kg})$.

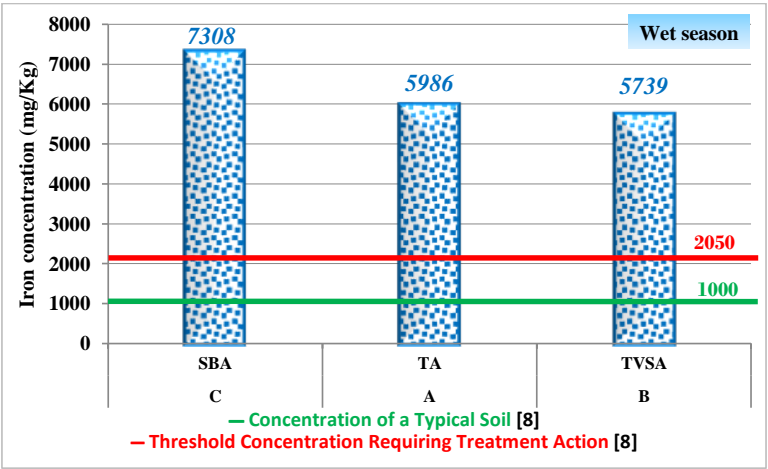

Fig. 5. Iron $(\mathrm{Fe})$ concentration measured during the wet season.

These enormous levels were also seen in the agricultural soils surrounding the mine waste storage site. The maximum Fe concentration was detected on the agricultural soil of Sidi-Boubker (zone 'C' at SBA), during the dry season $(7393 \mathrm{mg} / \mathrm{kg})$, while the minimum content was detected on the agricultural soil of the Touissit site with vegetation (zone 'B' at TVSA) (5893 mg/kg) (Figure 4). During the wet season, these maximum levels were recorded at the Sidi-Boubker site $(7308 \mathrm{mg} / \mathrm{kg})$, while the minimum levels were measured at the Touissit vegetated site $(5739 \mathrm{mg} / \mathrm{kg})$. The results showed that the minimum levels were recorded in the planted soils of the Touissit mine waste storage site, which affirms that vegetation has an important role in fixing metal pollutants and mitigating their negative effect in relation to the environmental receptacle. The maximum levels are noted in the mine waste storage site of the Sidi-Boubker site even in the soils that are $100 \mathrm{~m}$ from these mine waste storage sites. Indeed, this pollution is not punctual but it diffuses and reaches other vulnerable soils and leads to the contamination of agricultural soils, consequently threatens the fauna, flora and human health. Although iron is very vital for many animal or plant life processes being a precursor to the manufacture of DNA, the transport chain of respiratory electrons, also an element of oxygen storage and transport. However, the level of Fe above the threshold in the different tissues of the animal body can lead to pneumoconiosis, called siderosis [9] choroids, conjunctivitis, and retinitis [10] and the risk of lung cancer when ingested or inhaled by humans [11].

\section{Conclusion}

Trace metal components pose a risk to the environment and human health. The study conducted showed the spread of trace metal elements horizontally and also vertically. Metal pollution by a single physical or chemical change leaches off and into agricultural soils. These metallic elements deplete agricultural soils in nutrients. The studied site is an area known by a rarity of rain and strong winds that can disperse these pollutants further from the mine waste storage site, which are not physically or chemically stabilized. Finally, this type of metallic pollutant can be leached deeply and reaches the groundwater as well as posing a threat to the agriculture crop and livestock.

\section{References}

1. A. Smouni. Cah Agric, 19, 273-279 (2010)

2. M. Ater, A. HADI and P. Meerts, In: Conference: Biodiversity Hotspots in the Mediterranean Area: species, communities and landscape level. At: Cagliari. (2009)

3. M.R. Bouton. Visite aux mines de plomb de Zellidja. (1948)

4. A. Kriaa. Installations de traitement de la mine de Touissit. (1972)

5. R. Hakkou, M. Benzaazoua, 3-6 April 2012 Marrakech, Morocco tirée de ; Argane, Rabei Benzaazoua, Mostafa Bouamrane, Ahmed Hakkou, Rachid (2014). Valorisation des rejets miniers du district $\mathrm{Pb}-\mathrm{Zn}$ de Touissit-Boubker (région orientale-Maroc), 66, 38-44 (2012)

6. Handbook of Soil Analysis. pH Measurement. In: Springer, Berlin Heidelberg. (2006)

7. E. Marguı, I. Queralt, M.L. Carvalho, M. Hidalgo. Comparison of EDXRF and ICP-OES after microwave digestion for element determination in plant specimens from an abandoned mining area. Anal Chim Acta, 549, 197-204 (2005)

8. D. Baize, Références ET stratégies d'interprétation. Editions INRA. Paris. France, 408 (1997)

9. F. Archibald, FEMS Microbio. Let: 19, 29-32 (1983)

10. V. Braun, H. Killmann, Trends. Biochem. Sci, 24,104-109 (1999)

11. M.W. Hentze, M.U. Muckenthaler, N.C. Andrews. Cell, 117, 285-297 (2004) 